\title{
PANEL DISCUSSION: EDUCATION ON CONCEPTUAL MODELING FOR SIMULATION - CHALLENGING THE ART
}

\author{
Durk-Jouke van der Zee \\ Department of Operations \\ University of Groningen \\ Groningen, 9700 AV, THE NETHERLANDS
}

Mike Pidd

Department of Management Science

Lancaster University Management School

Lancaster, LA1 4YX, UNITED KINGDOM

Andreas Tolk

Dep. of Eng. Management \& Systems Eng.

Old Dominion University

Norfolk, VA 23529, USA

\author{
Kathy Kotiadis \\ Antuela A. Tako \\ Operational Research and Man. Sciences Group \\ Warwick Business School, University of Warwick \\ Coventry, CV4 7AL, UNITED KINGDOM
}

\author{
Osman Balci \\ Department of Computer Science \\ Virginia Tech \\ Blacksburg, VA 24061, USA \\ Mark Elder \\ Simul 8 Corporation \\ 141 St James' Road \\ Glasgow, G4 OLT, UNITED KINGDOM
}

\begin{abstract}
This panel seeks to initiate a discussion within the modeling and simulation community about the way we teach conceptual modeling for simulation with the view of bringing about improvements. The challenge addressed is how to educate and equip the novice analyst to become a professional rather than letting him become an artist - being very much the current practice. The need for professionalism is related to good quality research and education in a straightforward way. Emerging insights from literature on the relevance of conceptual modeling for project success, increasing system complexity, and stakeholders taking up an active role in conceptual modeling, further stress this need. This paper highlights key observations motivating the panel, and presents "position papers" on panelists' views on the way forward for education in conceptual modeling. The paper concludes with some themes from the viewpoints in the format of a SWOT (Strengths, Weaknesses, Opportunities and Threats) analysis.
\end{abstract}

\section{INTRODUCTION}

Conceptual modeling (CM) for simulation, boils down to a process of abstraction in which essentials of a real or proposed system are captured (Robinson 2008). As such it links the initial problem situation with the set up of a coded model and its intended use. Clearly, quality of the conceptual model is the foundation of every simulation study as it comes to its use and usefulness.

CM is certainly not easy (Law 1991). An important explanation may be in the fact that it requires bringing together domain specific knowledge and insights, starting from multiple disciplines, especially operations research, statistics, engineering, and computer science. Furthermore, modeling activities are 
subject to the specifics of the business context (budgetary constraints, resource availability, time frame etc.) and (possibly conflicting) stakeholder interests. Clearly, this puts high demands on the analyst's skills. In this panel session education of (novice) analysts in mastering just these skills will be addressed, by assessing the current situation and research needs. Here education refers to the use of discrete event simulation for supporting decision making on operations systems in (service) industry. More specifically, we consider courses, offered by academia, and training, as it is provided by consultancy firms.

This paper is structured as follows. In Section 2 we consider motivation for this panel. Next, in Section 3 panel set up is discussed. In Section 4 panelists state their positions. Finally, in Section 5, we shortly summarize main issues following from the position statements.

\section{MOTIVATION FOR THE PANEL SESSION}

In the introduction we set the focus of this panel session. In this section we provide some more background on the issue by considering the observations underlying the panel:

- The prevalent idea of CM being an art rather than a science: This finding is not surprising, given the aforementioned difficulties faced by the analyst in setting up a conceptual model. However, it is up to the modeling and simulation community to challenge the art, and allow the analyst becoming a professional, cf. Pace (2010).

- A lack of means for teaching support: Current teaching practice on CM seems to rely largely on teacher's experience rather than the general availability of adequate means (course/project formats, text books, case examples etc.). Most textbooks at best give a basic entry on CM, but offer little detail and no exercises. Also articles on education for CM are scarce.

- New needs - stakeholder involvement: New, chain-like configurations in manufacturing and services, like care chains, supply chains, and transportation networks assume concerted efforts of multiple stakeholders in coordinating overall system activities. New management concepts like lean and agile manufacturing stress staff involvement in solution creation. Apart from an increase of model complexity, these developments question the validity of the dominant "analyst only" approach in teaching on CM. Foremost, analysts should allow active stakeholder participation in CM by facilitating model understanding and use, cf. Van der Zee (2007), Jahangirian et al. (2010).

- Rising awareness among researchers of the relevance of $\mathrm{CM}$ for simulation project success: Awareness is expressed in terms of an increase of articles on the subject (where there are just a few), a first book providing a comprehensive view of the current state-of-the-art in CM supported by an interest group (Robinson et al. 2010), and dedicated sessions at conferences (for example, Winter Simulation Conference 2006-2008, 2010, and OR Society Simulation Workshop 20062010). Although the stream of papers is still small, it is steadily growing. The published work offers new means and relevant insights for CM by providing, for example, frameworks for setting up conceptual models in a step-wise manner, software engineering approaches for model specification, and techniques for problem and model structuring. However, research should make its way to education and practice, which is still considered by many as a challenge.

- Good quality modeling and simulation research: This session may be considered a follow up of recent panel discussions on good quality modeling and simulation research (Yilmaz et al. 2008, Yilmaz and Smith 2008, Smith et al. 2008) and the use of standards for modeling (Ehm et al. 2009). These panels express a need for "guidance" referring both to researchers attempting to do good modeling and simulation research, and their customers, i.e., analysts and stakeholders setting up, implementing and using simulation models respectively. Typically, authors express the need for guidance in terms of strategies, principles, methods, standards, tools and criteria. As such both panels set a frame of thinking for the current panel session focusing at research needs for improving education on CM. 


\section{PANEL DESCRIPTION}

Following the hypothesis that disciplines and teaching context (academia vs. consultancy firms) do matter in $\mathrm{CM}$ we set up a multidisciplinary panel, comprised of the following individuals:

- Durk-Jouke van der Zee (University of Groningen)

- Kathy Kotiadis (Warwick Business School)

- Antuela Tako (Warwick Business School)

- Mike Pidd (Lancaster University)

- Osman Balci (Virginia Tech)

- Andreas Tolk (Old Dominion University)

- Mark Elder (Simul8 Corporation)

All panel members are asked to respond with a position paper to the following four questions:

1. What makes good education on $\mathrm{CM}$ for simulation?

2. Is education on CM currently good?

3. How could education on CM be improved?

4. What should the Modeling and Simulation community do?

The questions are meant to facilitate an exploration of the state of play on education on CM in a SWOTlike (Strengths, Weaknesses, Opportunities and Threats) fashion.

\section{POSITION STATEMENTS}

\subsection{Durk-Jouke van der Zee (University of Groningen)}

\subsubsection{What Makes Good Education on Conceptual Modeling for Simulation?}

Simulation is part of the industrial engineer's toolbox for supporting systems design. CM links a system design with a conceptual model, i.e., the specification of an executable simulation model. The simulation model allows for the testing of alternative designs for their estimated (logistic) performance under various conditions. Here conditions may refer to, for example, demand figures, or system reliability.

Activities typifying CM for simulation are (i) determining modelling objectives, (ii) specification of model scope and detail, (iii) choice of output measures, and (iv) determining experimental factors. These activities build on the outcomes of the earlier phases in an industrial engineering project, i.e., problem definition, system description, and (initial) analysis. Modelling objectives have to be within the scope set by the project's problem definition. The specification of model scope and detail starts from the system description. System analysis supplies first insights in system performance relative to choices made on (current) system configuration and its planning and control. Many deterministic techniques are available here like lead time analysis, or more specific, set up time analysis. Insights underpin choice of alternative designs (experimental factors) and choice of output measures, capturing performance, and its underlying causes.

CM activities as specified here are largely in line with those specified by Robinson (2008). Differences are in the explicit linking of activities to industrial engineering projects phases. Furthermore where Robinson assumes identifies an activity "understanding the problem situation", I do not do so, assuming this to be covered within the larger project context, especially problem definition, and analysis.

Let me now consider learning objectives, starting from the above informal definition of CM for simulation and an industrial engineering context. In my view learning objectives should include two main 
elements, i.e. (i) student's knowledge with respect to methods, techniques and insights relevant for specific modelling activities, (ii) student's skills in executing activities, thereby making good use of supportive means, and resources.

Essential supportive means for CM activities would be stepwise approaches for model specification, and standards for its notation. Modelling principles suggesting evolutionary model development or model pruning are helpful in system abstraction (Pidd 1999, Robinson 2008). Project management and communicative means are relevant because of a conceptual model not only being a specification but also involving a decision, creating a foothold for later project stages.

Typically, student skills do not only appeal to good use of aforementioned means, they also assume integrated use of prior knowledge and insights obtained from several fields, i.e., statistics, logistics management, operations research and engineering. Note how such an integrated approach sets demands on both simulation course(s) set-up and its embedding within a curriculum. In turn, such an integrated approach should be reflected in teaching materials, for example, text books and case examples.

\subsubsection{Is Education on Conceptual Modeling Currently Good?}

Current education on CM almost solely builds on the teacher's skills and interests. Supportive means such as text books, case examples are hardly available. In many cases teaching may boil down to an art being passed on to students. Or even worse, the subject is hardly treated at all, given the lack of means, and/or resources, i.e. course credits. The latter point refers to a situation where (basic) courses are dominated by the coding exercise, i.e., students efforts in mastering simulation software, or, to a lesser degree, statistics associated with model elements or outputs. Hence little time is left for CM. Some people may even say little time is "required" as case examples often boil down to close reading rather than modelling.

Part of the "damage" in basic courses may be repaired in follow-up courses, for example, student projects in industry. Typically, the need for CM is greater here, given system complexity and the "real" business context. Although attention for CM is greater here and also students may be convinced of its great relevance, students still rely on the skills of the teacher in his role of the project mentor/skilled artist. Clear standards, on procedures, notation, and model qualities are simply lacking.

\subsubsection{How Could Education on Conceptual Modeling Be Improved?}

Building on the above observations, education on $\mathrm{CM}$ is in great need of teaching materials that embed (i) a clear definition of CM (possibly adapted for a discipline), (ii) well-defined standards for procedures, notation, and model qualities, (iii) good modelling principles. Furthermore, teaching means should support an integrated approach towards modelling, cf. Section 1.1.

Next to a lack of qualified means other problems to be solved may be in course and curriculum formats and resources, which hinder sufficient attention for this subject. Making the role and relevance of $\mathrm{CM}$ explicit in literature, and in course text books is an important first step in changing this situation.

\subsubsection{What Should the Modeling and Simulation Community Do?}

In past decades only few efforts were put into research on CM. Recently, however, research on CM for simulation gained some momentum, building on the efforts of a few dozens of researchers (Robinson et al. 2010). Although efforts are scattered over disciplines, fields of interest, and modelling activities addressed, they provide an initial basis for further research and educational support. Basic challenges for the Modelling \& Simulation Community are in concerted efforts directed to:

- Explicit acceptance of CM as a key field of interest within the community, by, for example, making it a default conference track, and regular issue addressed in simulation journals.

- Cluster efforts of researchers in interest groups. 
- Educate the researchers, for example by offering, tutorial at major conferences.

- Clear standards for CM starting from a stakeholder view, and linking to other simulation modelling stages and the project context at large.

- Develop and test teaching means.

- Give room for research on education for CM.

\subsection{Kathy Kotiadis, Antuela A. Tako (Warwick Business School)}

\subsubsection{What Makes Good Education on Conceptual Modeling for Simulation?}

The definition of conceptual modeling adopted for this view is based on the definition proposed by Robinson (Robinson 2008). We embrace the view that conceptual modeling is the process undertaken to reach to the conceptual model, which is the output of this process. Robinson identifies a number of processes undertaken as part of conceptual modeling, each leading to an output, for example the process undertaken to understand the problem situation leads to gaining an understanding of the problem situation. Having said that, there are many ways to 'skin a cat'! Each process in Robinson's definition can be undertaken in many ways, each of these leading to the output. The research in CM has largely moved from 'what is CM about' to 'how should it be done' and will probably continue to be of particular interest until theory and academic papers turn into teaching materials and common practice.

This viewpoint proposes that the interest in CM should not only relate to the process of CM but also on the format of the conceptual model. The format of the conceptual model is important as it is generally communicated to the clients/stakeholders/subject matter experts for approval before moving on to the model coding part of the study (Onggo 2009). Furthermore, conceptual model validity is a key process of validation and verification, which brings an added reason to aim for the best possible format.

Therefore this viewpoint also proposes that a typical simulation student should be taught: a) the stages of $\mathrm{CM}, \mathrm{b}$ ) the process and tools that can be used in each stage of the process to reach the conceptual model, c) one or more formats to represent the conceptual model, d) how to communicate the conceptual model to the client(s) and e) how to ensure conceptual model validity. Currently, a student first encountering discrete event simulation on a taught course will probably be formally taught in full or partly a), c) and e) but will only really understand and experience all these learning objectives (a-e) if they undertake a real life simulation study for a real client. Our viewpoint is that ideally an undergraduate student should expect to be taught CM in order to reach an understanding of all the learning objectives but a Masters level student intending to become a DES modeler should be given the opportunity to also experience these learning objectives (table 1). In an ideal world this would mean undertaking real life projects but realistically this may not be possible but real life case studies can be an option.

Table 1: What should a future simulation practitioner expect from a UG and PG degree?

\begin{tabular}{|l|l|l|}
\hline Level & Minimum experience of CM & CM Learning objectives \\
\hline Undergraduate & Taught & a-e \\
\hline Masters & Taught + Opportunity to practice & a-e \\
\hline
\end{tabular}

\subsubsection{Is Education on Conceptual Modeling Currently Good?}

The education on $\mathrm{CM}$ is probably on the whole weak compared to the other simulation study processes such as model coding, experimentation, etc., mainly because we have not yet completed the minimum research required for it to become less of an art and more of a science. In addition, from the educator's point of view it is easier to demonstrate the more tangible elements of a simulation course such as the model coding. Also, the students, once they are introduced to simulation, are keen to learn about and use the 
VIM software and are less concerned about CM until they actually experience it in real practice. It does not help that nowadays students are clients and there is a pressure on educators to provide students with a satisfactory learning experience, which can mean giving them more of what they enjoy.

\subsubsection{How Could Education on Conceptual Modeling Be Improved?}

Our viewpoint is that in order to improve the way $\mathrm{CM}$ is currently taught the following are required:

- More research so that CM is fully understood and transparent.

- More evidence of CM in practice.

- Identify methods for teaching modeling skills effectively (how to be a good modeler).

- Examples of CM teaching and how to make it more appealing to students (how to demonstrate the added value on $\mathrm{CM}$ in practice).

\subsubsection{What Should the Modeling and Simulation Community Do?}

The first couple of improvements suggested above (III) could be speeded up if good OR journals put CM special issues such as the Journal of Simulation in 2007. This would encourage a larger cohort of academics to engage in the issues and demonstrate to the simulation community that CM is just as important as other research going on in simulation. The final two improvements (III) can be tackled at specialist simulation conferences such as WSC10 and SW12, with this panel in 2010 being a step in the right direction.

\subsection{Mike Pidd (Lancaster University)}

\subsubsection{What Makes Good Education on Conceptual Modeling for Simulation?}

There are clearly many different definitions of CM. My own preference is to focus on conceptualization as a process that has two main elements: learning and representation. Most theories of learning, correctly in my view, stress two aspects:

1. Learning is cyclic; that is we keep worrying away at something, revising our understanding until we've made enough progress to use whatever we've learned.

2. Learning usually proceeds in steps, rather as a smooth ascent to higher planes of knowledge. Thus we are initially baffled or puzzled, like looking up a rock face, but then we find that we've made progress, though often we're unsure how. Then we look up again ...

Model representation involve us capturing whatever we've learned or think that we know, and expressing it externally in a way that is accessible to other people and, possibly, to computer software.

If we combine these views of learning and representation, $\mathrm{CM}$ is a process in which we gradually develop our understanding of a system that is to be modeled and the reasons for doing so. In doing this, we develop different representations that we refine into something that is good enough for the purpose at hand. This is often a slightly chaotic and iterative process that can be helped by experience, by appropriate tools and by interaction with other people. Unless the simulation application is trivial, the conceptual model that is actually used is unlikely to be clear at the start. Sometimes, though we don't like to admit it, the conceptualization is only clear after the event. In summary, CM is modeling.

In discrete simulation, the aspects that require representation are the entities within the system and their interactions. There are several ways in which these elements can be captured, but they must be found somewhere in the representation. This suggests that we need our students to develop at least the following capabilities. 
1. A systems/process worldview: they need to understand that the relationships between elements are as important as the elements themselves and need to understand which are important and must be included, and which can be omitted.

2. An appreciation that the intended end use of a model will be the major determinant of the level of detail needed in the representation.

3. An understanding that the real world is messy and that a perfect model is a lovely idea but unlikely to be developed, because of time and resource constraints.

4. A feel for the effects of uncertainty and variability, which is very different from the ability to perform statistical calculations according to recipes.

How to achieve these outcomes? It depends on the students with whom we are working. My background is in OR/MS and I usually teach simulation to students who are also learning about other approaches such as mathematical programming, data mining, stochastic processes and statistical analysis. Thus I can refer to these in my teaching, which makes life much easier, since I can use to some useful insights from those areas.

We are fortunate to have simulation software that is easy to use and supports iterative model development. This may upset some purists, but I think we can use this software in one of two ways. We can either keep students away from it as long as possible, in the hope that this will develop their conceptualization skills before they put hand to mouse. Or, we can let them loose on the software early and keep stopping them to raise issues of conceptualization. I know of no evidence that shows one approach is better than the other.

Clearly, any attempt achieve the four objectives listed above will require mixed means, including teaching from the front; small-scale exercises that start simple and become complex; and an attempt to develop a 'real' simulation model. The last element is, I think, particularly important and I'm grateful to my Lancaster colleague, Roger Brooks, for including a mandatory simulation project in our simulation courses. The students work in small teams, select a system that they think would benefit from simulation analysis and, with some guidance, develop and use a model. Some do it better than others, but all seem to learn a lot. Some students really enjoy the experience and want to do more; others hate it and are put off simulation for life.

\subsubsection{Is Education on Conceptual Modeling Currently Good?}

My honest answer is that I don't know whether CM education is good or not and therefore do not know whether it can be improved. I've been involved in simulation education, practice and research for over 30 years and have seen quite a few helpful changes over that period. Simulation software is now much easier to use and encourages students to take a process view of entities and their interactions, which was not really true of previous software. It also, as mentioned earlier, allows iterative model development.

Likewise, simulation texts have changed over that period. I started to write the first edition of Computer Simulation in Management Science in 1982 because I was frustrated that the then available books put too much stress on the statistical aspects of discrete simulation and also ignored system dynamics. In teaching students I was aware that conceptualization, using tools such as activity cycle diagrams, might help them to develop better models and increase their understanding of what went inside the black box of simulation software. Since then, others have taken up the same reins.

We should also recognize that doing good work in discrete simulation is difficult. It requires competence in computing and statistics and skills in conceptualization. If we teach the three hand-in-hand, we stand a chance of improving simulation education.

\subsubsection{How Could Education on Conceptual Modeling Be Improved?}

See Section 4.3.2. 


\subsubsection{What Should the Modeling and Simulation Community Do?}

One of the very first texts on discrete event simulation was Tocher's The Art of Simulation (Tocher 1963). Its title is significant, since it uses the word Art, not science. I'm told by those who knew Keith Tocher that he rather hoped it would become more of a science and less of an art as knowledge developed and tools improved. However, we should recognize that there is still a large art and craft component to simulation model development and use and that this is important when providing education in CM.

\subsection{Osman Balci (Virginia Tech)}

\subsubsection{What Makes Good Education on Conceptual Modeling for Simulation?}

The role of a conceptual model within the modeling and simulation (M\&S) life cycle has been more widely recognized and emphasized only during the last decade. Based on recent research activities, disparate definitions have been proposed for conceptual model and CM (Balci, Arthur and Nance 2008; Balci and Ormsby 2007; Robinson et al. 2010). We provide our definitions here.

A simulation Conceptual Model is a repository of high-level conceptual constructs and knowledge specified in a variety of communicative forms (e.g., animation, audio, chart, diagram, drawing, equation, graph, image, text, and video) intended to assist in the design of any type of large-scale complex M\&S application. The targeted users of a conceptual model can include M\&S application designers, M\&S project managers, and $\mathrm{M} \& \mathrm{~S}$ analysts. A conceptual model should be created for a Community of Interest (COI) such as air traffic control, automobile manufacturing, ballistic missile defense, business process reengineering, emergency response management, homeland security, military training, network-centric operations and warfare, supply chain management, telecommunications, and transportation. The lead organization of a COI is expected to fund the development and maintenance of a conceptual model.

Simulation Conceptual Modeling is the process by which a simulation Conceptual Model is created. We advocate that the verification, validation, and quality assurance strategy be adopted from the perspectives of 4 Ps involving the assessment of the:

- Conceptual model specification as an output work product (artifact),

- Conceptual modeling as a process used in creating the output work product,

- Quality of the people employed in conceptual model development, and

- $\quad$ Project characteristics such as configuration management, risk management, planning, documentation, and effective utilization of subject matter experts.

Having successfully completed a course on simulation conceptual modeling, students should be able to:

1. Develop a simulation conceptual model to

a) assist in designing not just one $\mathrm{M} \& \mathrm{~S}$ application but many in a particular COI (problem domain),

b) enable reusability and composability throughout $\mathrm{M} \& \mathrm{~S}$ development,

c) enable effective communication among the people involved in a large-scale M\&S project such as stakeholders, potential users, managers, analysts, and M\&S developers,

d) assist in overcoming the complexity of designing large-scale complex M\&S applications in a COI, and

e) assist in verification, validation, and certification of the M\&S application.

2. Execute the verification, validation, and quality assurance strategy stated above.

3. Manage a simulation conceptual modeling project.

4. Work on an M\&S project with the title of Conceptual Model Engineer. 
Van der Zee, Kotiadis, Tako, Pidd, Balic, Tolk and Elder

\subsubsection{Is Education on Conceptual Modeling Currently Good?}

See 4.4.1

\subsubsection{How Could Education on Conceptual Modeling Be Improved?}

A course on simulation conceptual modeling should start by describing the role of conceptual modeling in other disciplines. For example, conceptual design precedes any engineering design activity and is very commonly employed in the engineering disciplines. Similarly, a simulation conceptual model precedes a simulation model design. Such analogy helps the students better comprehend the role and importance of conceptual modeling.

The course would be most effective if real-life examples are included. Bringing subject matter experts as guest lecturers would also provide significant value to the learning process. An education on modeling is never complete without proper coverage of verification, validation, and quality assurance. Hands-on inclass active learning sessions should be employed as much as permitted by the duration of the course. Such sessions are known to improve the effectiveness of learning significantly. Passive learning approaches should be avoided as much as possible. Student's active involvement in the learning process during classroom sessions or lectures is critically needed.

\subsubsection{What Should the Modeling and Simulation Community Do?}

See 4.4.3.

\subsection{Andreas Tolk (Old Dominion University)}

\subsubsection{What Makes Good Education on Conceptual Modeling for Simulation?}

In order to answer the question about good education on CM, first a good definition for a conceptual model is needed. Establishing a body of knowledge for CM, which means to establish a comprehensive and concise representation of concepts, terms, and activities that make up a professional CM domain, is not an easy task. Examples of such efforts are given by Robinson (2008). CM is often understood as an effort that happens before systems are built or software code is written. Consequently, conceptual models are primarily described as mental models that are used in an early stage in the abstraction or as a simplification process in the modeling phase. However, this conceptual model is a purposeful abstraction and simplification of reality, capturing constraints and assumptions resulting in a conceptualization of the problem to be solved, the environment in which it has to be solved, and relevant actors, their behavior, and the relationships of interest to solve the problem. It has been shown in recent $\mathrm{PhD}$ studies by King (2009) that it is not only possible but necessary to capture assumptions and constraints in order to avoid conceptual misalignments when two model-based solutions are composed only based on implementation specifications. What therefore is needed is a formal specification of the conceptualization on the logical level, which translates into the requirement to be able to handle ontological means. Davis and Anderson (2003) point out, conceptual models should be documented based on engineering methods enabling their interpretation and evaluation by other engineers, or in Davis and Anderson's words a "fully specified but implementation independent model." Only if the conceptual model is captured using agreed to sufficient technical means, it is possible to evaluate if two systems are conceptually alignable or not, and only if this specification is machine understandable, intelligent software can help in identifying applicable solutions, select the best ones, support their composition, and orchestrate their execution as envisions in web-based solutions.

However, the ability of using tools to develop an ontology is necessary, but not sufficient. The ontology itself is only a technical mean to capture the process of abstraction and simplification. Good educa- 
tion must also enable the student to successfully build a conceptualization in support of solving a problem. Tolk et al. (2008) described various layered approaches used in related domains. The students should know these models and their use to guide them in the process of conceptualization. A mistake made quite often - even by educators - is to confuse the process of conceptualization with the application of modeling paradigms or methods. If a certain paradigm is used, e.g., system dynamics, the conceptualization is no longer implementation independent but driven by the world view of this paradigm. Conceptualization using the Unified Modeling Language (UML) has a different expressiveness than conceptualization using Petri-Nets. Each modeling support comes with a limiting syntax and semantic, and the student must be aware of these limitations. Good education must teach potential as well as limitation of tools, methods, and paradigms.

\subsubsection{Is Education on Conceptual Modeling Currently Good?}

In particular students of technical domains within engineering and computer science are often not sufficiently aware of findings in other disciplines. While management and social sciences emphasize the need for a post-positivistic worldview, many students of technical simulation disciplines are still driven by the idea that there is exactly one world that can be modeled as a synthetic environment, and that there are real systems in this world that can be modeled as entities in this synthetic environment. Different models exist in their mindset because the same aspects were simply interpreted differently, abstracted differently, or simplified differently. However, as they are all derived from the same "real" world, there is assumed to have always a way to match them all back together somehow. Currently, many efforts in technical disciplines try to establish common terms, common data models, common exchange protocols, or a common ontology to enable the easy composition of independently developed solutions by mapping them back to the assumed common reality. However, modern science started at the end of the last century to move farther and farther away from these ideas. The mindset of one single unambiguously expressively truth is no longer driving sciences, and not even language itself is considered to be a reliable means to communicate truth. This more philosophical background and its application need to be included into the advanced education of CM foundations. We can and should no longer assume one common reality that can be expressed in one guiding common Übermodel that can lead to all other models by pruning and aggregation. Each one of our models expresses an individual consistent internal reality. The conceptual model expresses this specific viewpoint and must become the basis for composition decisions, as Tolk et al. (2010) show.

\subsubsection{How Could Education on Conceptual Modeling Be Improved?}

The special role of modeling in general and CM in particular are currently not emphasized enough in M\&S education. Too often, the emphasis still lies on simulation and implementation questions. The education is driven more by computer science than by other contributing disciplines. Computer simulation is often perceived as a special branch of computer applications, and CM focuses on teaching UML or another tool to specify the implementation. The awareness of the special role of modeling and the difference of $M \& S$ from other programs is not in the heads of educators, and hence not in the mindset of students. A good programmer for business applications is not necessarily a good fit for M\&S applications. The conceptualization that leads to the model and the simulation represents the reality encoded in the system and as such becomes for M\&S as important as the reference system for other IT solutions. That is the reason for many developers still having the mindset that the conceptual model is just a preliminary first idea that is no longer needed once the implementation has been accomplished. Why this perception is critically wrong for model-based solutions has been discussed in the earlier paragraph, but the paradigm shift did not translate in education guidelines so far. This is a problem that needs to be addressed to increase the quality of education in modeling in general and $\mathrm{CM}$ in particular. 


\subsubsection{What Should the Modeling and Simulation Community Do?}

To make a change, the $M \& S$ community first needs to become aware of such challenges itself. Science philosophy and its relation to $M \& S$ is not yet part of any curriculum the author of this section is aware of. However, the self perception of an M\&S expert to be something special is the driving force behind making $M \& S$ a discipline. $C M$ outside of $M \& S$ is likely to remain mental models used early in the development process. Conceptual models inside of $\mathrm{M} \& \mathrm{~S}$ with the mindset envisioned in this contribution become the foundation of the discipline and the yardstick for modeling expertise, composability of models, and expression of post-positivistic science in new application domains, such as using models to derive new theories and generate knowledge, as envisioned by Ören (2009) and shown applied within recent research in Padilla (2010). Good education must lay the foundation in form of philosophical ideas and awareness of potential and limitations of paradigms, methods, and tools. We need to know and educate what we can model, what it means to conceptualize in the post-positivistic world, that the formal specification of our conceptualization defines the implemented world-view of a model-base solution, and how we can express our conceptual model in machine readable form to support identification, selection, composition, and orchestration of model-based solutions.

\subsection{Mark Elder (Simul8 Corporation)}

\subsubsection{What Makes Good Education on Conceptual Modeling for Simulation?}

$\mathrm{CM}$ is the distillation of Problem Objectives and Problem Situation into the Simplest Useful Simulation Model because the simpler the model the more directly it will create learning in the client organization (because it will be direct, agile, and available in a short time frame).

Many new graduates are very good at the technical aspects of building simulation models. The learning objective should be that new graduates are just as good at CM. The problem right now is that a poor Conceptual Model means they build a highly accurate, but wrong, simulation model. But, this objective is really difficult, because it is quite a black-art and I have always found it very difficult to get people to do it enough, especially early in their careers. That statement applies to both consultants who I have managed and customers who do modeling work (and who I'd prefer to get Conceptual Models correct). Partly I believe people only gets good at CM with experience. However, there are a few guidelines that do help people with CM. So educators should teach the guidelines and give plenty of examples (perhaps as exercises) to build experience. I suspect we can have a long debate on the guidelines, but I have found these work:

- Refuse to respond to requests for simulation models “...of my whole process so I can try out any idea in the future" as simulation models for general purposes are never useful when a specific purpose comes along.

- Ask your client "What would be a measure of success in your process?" (this leads to finding out what they do and don't like about the current situation and therefore what the real objective of the study is).

- Ask your client "What are you willing to change?" (in other words "what are the decision variables?").

- Then go for a walk around the process, you will find lots of things the client forgot to mention that impact the objective, on the other hand the client will mention lots of things they want in the simulation model that you will ask "could that really affect the decision?"

- Build a quick simulation model at the end of the walk around the process, including things you think impact the decision (be strict to exclude things that might impact the outcomes in only small ways and therefore would not actually impact the outcome of the decision). Obviously also exclude data and any detail that would cause you to take more than a few minutes building the si- 
mulation model. Discuss this model with the client and see what else emerges into the conversation.

- Get samples of data from your client (most of them will have a few spreadsheets of data, most columns of which will be irrelevant to your needs - but this is much more informative than asking your client for specific pieces of data which then they can't extract from their systems. The nature of the actual data will tell you more about the process.

- Now go away and write out in table form what you will and will not include in the simulation and why. Include some logic flow diagrams to capture your understanding of any intricate control rules (if any). This document is your conceptual model and should be included as part of a formal specification of the project you will undertake.

- Don't let building the Conceptual Model get in the way of building the real model and solving the problem remembering that, for real decision making, speed of making the model available, and therefore the results available, and therefore the client's learning happen, is possibly more important than the accuracy of the results.

- Also recognize that the act of doing all of the above will be a powerful experience for most clients, I've seen a lot of cases where the work to create the Conceptual Model asks the client sufficiently detailed questions, that had not been asked before, for them to work out what the solution is to their problem before you have built the simulation model!

In line with the above suggestions, relevant for education means to be case-based. While I'd be very happy to run mentoring projects I don't think real projects are short enough for student learning and I don't think we are good at teaching it to our own people. What is needed is loads of small cases with examples of where it went wrong because CM was not done properly. Subjective and qualitative aspects of modeling are successfully taught in modeling disciplines, so I don't see why it can't be done for CM.

\subsubsection{Is Education on Conceptual Modeling Currently Good?}

I suppose not, because I'm not seeing people fresh to their career doing it effectively (Or even trying to do it at all).

\subsubsection{How Could Education on Conceptual Modeling Be Improved?}

I have spent almost no time researching what the current methods are that are really used, but looking at the available texts, there still seems to be a significant reliance on very early diagramming methods just as Activity Cycle Diagrams. It really is time we moved away from methods that only work on problems so simple that they would not be useful on real client issues, also see Section 4.6.1.

\subsubsection{What Should the Modeling and Simulation Community Do?}

Create a Wiki where we can build a community based library of case studies.

\section{SUMMARY}

The paper has put forward a number of individual's views on education in CM in line with a set of questions to establish the current situation and the way forward. The views on each question are multidimensional (but hardly ever in opposition to each other) as their represent academics of different disciplines (computer science, engineering, operational research/management science) and industry. This is hardly surprising and goes to show that the answer to each question cannot be summarized by a single viewpoint and that education in CM is the community's concern. In an effort to bring about some overarching conclusions from the viewpoints, we put forward some themes that have repeated within the viewpoints in the format of a SWOT (Strengths, Weaknesses, Opportunities and Threats) analysis (Table 2). 
Table 2: A SWOT analysis of education in conceptual modelling representing the views of this paper

\begin{tabular}{|c|c|}
\hline $\begin{array}{l}\text { Strengths } \\
\text { - Agreement that education in CM is im- } \\
\text { portant and needed } \\
\text { There is ongoing research in CM (aca- } \\
\text { demics have started to engage in re- } \\
\text { search in CM) } \\
\text { The problem of providing good CM edu- } \\
\text { cation is not insurmountable }\end{array}$ & $\begin{array}{l}\text { Weaknesses } \\
\text { - } \quad \text { Education dependent on teacher at each institu- } \\
\text { tion } \\
\text { - } \quad \text { DES focussed on teaching use of software. } \\
\text { - } \quad \text { Weak embedding of CM in curricula } \\
\text { - } \quad \text { Lack of standards } \\
\text { - Little/no attention for CM or mental modelling } \\
\text { - } \text { only } \\
\text { - } \quad \text { modity issues hardly addressed, for example, } \\
\text { - } \text { - Stakeholders' interests and involvement in CM } \\
\text { - Specification methods taught may not be ade- } \\
\text { quate given business complexity }\end{array}$ \\
\hline $\begin{array}{l}\text { Opportunities } \\
\text { - } \quad \text { To develop more standards and tools in } \\
\text { order to provide transparency in the CM } \\
\text { processes } \\
\text { - } \quad \text { Conferences to host regular sessions on } \\
\text { CM } \\
\text { - } \quad \text { Journal special issues on CM } \\
\text { - } \quad \text { To create and share library of CM case } \\
\text { studies and other teaching materials fos- } \\
\text { tering active learning (e.g. WIKI) }\end{array}$ & $\begin{array}{l}\text { Threats } \\
\text { - } \quad \text { M\&S field driven by computer science } \\
\text { - } \quad \text { Research base too small for education to benefit } \\
\text { plines. }\end{array}$ \\
\hline
\end{tabular}

\section{REFERENCES}

Balci, O., J.D. Arthur and R.E. Nance. 2008. Accomplishing reuse with a simulation conceptual model. In Proceedings of the 2008 Winter Simulation Conference, ed. S. J. Mason, R. Hill, L. Moench, and O. Rose, 959-965. Piscataway, New Jersey: Institute of Electrical and Electronics Engineers, Inc.

Balci, O., and W. F. Ormsby. 2007. Conceptual modeling for designing large-scale simulations. Journal of Simulation 1(3): 175-186.

Davis, P.K. and R.H. Anderson. 2003. Improving the Composability of Department of Defense Models and Simulations. Report. Santa Monica, CA: RAND Corporation.

Ehm, H., L. McGinnis, and O. Rose. 2009. Are simulation standards our future? In Proceedings of the 2008 Winter Simulation Conference, ed. M. D. Rossetti, R. R. Hill, B. Johansson, A. Dunkin and R. G. Ingalls, 1695-1702. Piscataway, New Jersey: Institute of Electrical and Electronics Engineers, Inc.

Jahangirian, M., T. Eldabi, A. Naseer, L.K. Stergioulas, and T. Young. 2010. Simulation in manufacturing and business: A review. European Journal of Operational Research 203(1): 1-13.

King, R.D. 2009. The Role of Assertions for Conceptual Modeling as Enablers of Composable Simulation Solutions. Doctoral Thesis. Norfolk, VA: Old Dominion University.

Law, A.M. 1991. Simulation model's level of detail determines effectiveness. Industrial Engineering 23(10): 16-18.

Onggo, B. S. S. (2009). Towards a unified conceptual model representation: a case study in healthcare. Journal of Simulation 3(1): 40-49. 
Ören, T. 2009. Modeling and simulation: A comprehensive and integrative view. In Agent-Directed Simulation \& Systems Engineering, ed. L. Yilmaz and T. Ören, 9-45. New York, NY: John Wiley \& Sons.

Pace, D.K. 2010. Conceptual Modeling Evolution within U.S. Defense Communities: The View from the Simulation Interoperability Workshop. In Conceptual Modelling for Discrete-Event Simulation. ed. Robinson S., Brooks, R.J., Kotiadis, K., and D.J. van der Zee. Boca Ration: CRC/Taylor \& Francis.

Padilla, J. 2010. Towards a Theory of Understanding Within Problem Situations. Doctoral Thesis. Norfolk, VA: Old Dominion University.

Pidd, M. 1999. Tools for Thinking - Modelling in Management Science. 2nd ed. Chichester: Wiley.

Robinson, S. 2008. Conceptual modelling for simulation Part I: definition and requirements. Journal of the Operational Research Society 59(3): 278-290.

Robinson S., R.J. Brooks, K. Kotiadis, and D.J. van der Zee. 2010. Conceptual Modelling for DiscreteEvent Simulation. Boca Ration: CRC/Taylor \& Francis.

Smith, J.S., J.A. Hamilton, R.E. Nance, B.L. Nelson, G.F. Riley, and L.W. Schruben. 2008. Panel discussion: What makes good research in modelling and simulation: assessing the quality, success, and utillity of M\&S rersearch. In Proceedings of the 2008 Winter Simulation Conference, ed. S. J. Mason, R. Hill, L. Moench, and O. Rose, 689-694. Piscataway, New Jersey: Institute of Electrical and Electronics Engineers, Inc.

Tocher, K.D. 1963. The Art of Simulation. London: English Universities Press.

Tolk, A., S.Y. Diallo, and C.D. Turnitsa. 2008. Mathematical Models towards Self-Organizing Formal Federation Languages based on Conceptual Models of Information Exchange Capabilities. In Proceedings of the 2008 Winter Simulation Conference, ed. S. J. Mason, R. Hill, L. Moench, and O. Rose, 966-974. Piscataway, New Jersey: Institute of Electrical and Electronics Engineers, Inc.

Tolk, A., S.Y. Diallo, R.D. King, C.D. Turnitsa, and J. Padilla. 2010. Conceptual Modeling for Composition of Model-based Complex Systems. In Conceptual Modelling for Discrete-Event Simulation, ed. S. Robinson, R. Brooks, K. Kotiadis, and D.J. van der Zee. Boca Ration: CRC/Taylor \& Francis CRC Press.

Van der Zee, D.J. 2007. Developing participative simulation models - framing decomposition principles for joint understanding. Journal of Simulation 1(3): 187-202.

Yilmaz, L., and J. Smith. 2008. Prelude to the panel on what makes good research in modelling \& simulation. In Proceedings of the 2008 Winter Simulation Conference, ed. S. J. Mason, R. Hill, L. Moench, and O. Rose, 671-676. Piscataway, New Jersey: Institute of Electrical and Electronics Engineers, Inc.

Yilmaz, L., P. Davis, P.A. Fishwick, X. Hu, J.A. Miller, M. Hybinette, T.I. Ören, P. Reynolds, H. Sarjoughian, and A. Tolk. 2008. Panel discussion: What makes good research in modelling \& simulation: sustaining the growth and vitality of the M\&S discipline. In Proceedings of the 2008 Winter Simulation Conference, ed. S. J. Mason, R. Hill, L. Moench, and O. Rose, 677-688. Piscataway, New Jersey: Institute of Electrical and Electronics Engineers, Inc.

\section{AUTHOR BIOGRAPHIES}

DURK-JOUKE VAN DER ZEE is associate professor of Operations at the Faculty of Economics and Business, University of Groningen, The Netherlands. He received his MSc and PhD in Industrial Engineering at the University of Twente, The Netherlands. His research interests include simulation methodology and applications, simulation \& serious gaming, manufacturing planning \& control, and design and control of flexible manufacturing systems. He is a member of INFORMS_SIM and SCS. His email address is $<\mathrm{d} \cdot j \cdot \mathrm{van}$. der, zee@rug.nl $>$.

KATHY KOTIADIS is an assistant professor at the Warwick Business School (UK) and co-chair of the UK Simulation Special Interest Group. She holds a BSc and PhD from the University of Kent. Her main research interests include health service modelling and combining problem structuring approaches with DESM. Her email address is <kathy • kotiadis@wbs . ac . uk>. 
ANTUELA A. TAKO is a Research Fellow at the University of Warwick. She holds a PhD in Simulation and an MSc in Management Science and Operational Research from the same University. Her research focuses on the simulation model building process, conceptual modelling and other simulation approaches. Her email address is <antuela.tako@wbs. ac . uk>.

MIKE PIDD is Professor of Management Science in Lancaster University Management School in the UK. His research spans several areas, including computer simulation, healthcare systems modeling and theories of modeling and model use, on which subjects he has written widely. He gave a Simulation Titan talk at WSC08 and is a past-President of the UK Operational Research Society. His email address is $<$ m.piddelancaster.ac.uk>

OSMAN BALCI is a Professor of Computer Science at Virginia Polytechnic Institute and State University (Virginia Tech). He received B.S. and M.S. degrees from Boğaziçi University (Istanbul) in 1975 and 1977, and M.S. and Ph.D. degrees from Syracuse University (New York) in 1978 and 1981. Dr. Balci currently serves as an Area Editor of ACM Transactions on Modeling and Computer Simulation, Modeling and Simulation (M\&S) Category Editor of ACM Computing Reviews, and Editor-in-Chief of ACM SIGSIM M\&S Knowledge Repository. His current areas of expertise center on Software Engineering (iPhone, net-centric, IV\&V), Architecting system of systems, M\&S (methodology, V\&V, certification). His e-mail address is <balci@vt.edu>.

ANDREAS TOLK is Associate Professor for Engineering Management and Systems Engineering of Old Dominion University. He is also a Senior Research Scientist at the Virginia Modeling Analysis and Simulation Center. He holds a M.S. in Computer Science (1988) and a Ph.D. in Computer Science and Applied Operations Research (1995), both from the University of the Federal Armed Forces of Germany in Munich. He is a member of ACM SIGSIM, ASEM, MORS, NDIA, SCS and SISO. His e-mail address is <atolk@odu.edu>.

MARK ELDER founded SIMUL8 Corporation in 1994 following a career in two other simulation companies and as a simulation academic. He has an education in Operations Research and a PhD from University of Strathclyde in Scotland where he is still a Visiting Academic. His company puts significant resource into academic and research collaborations in terms of both time and financial contributions to joint funding with research grant bodies. His research interests almost all relate to getting simulation in the hands of end decision makers. His email address is <mark . e@ S IMUL 8 . com>. 